\title{
Measurement of change in body-weight
}

\author{
By T. KHOSLA* AND W. Z. BILLEWICZ \\ Obstetric Medicine Research Unit (MRC) and Research Group in \\ Biometric Medicine, University of Aberdeen
}

\section{(Received 20 September 1963-Accepted 14 November 1963)}

In clinical practice and in metabolic research, it is often necessary to determine whether body-weight has changed, and if so by how much, during the period of observation. Unless the changes are gross, single measurements at the beginning and the end of the period may be misleading because the trend of weight is obscured by rapid fluctuations from day to day. 'These fluctuations may be quite large. For example, Elkinton \& Danowski (r955) in a study of one man recorded changes as high as I $\mathrm{kg}$ from one day to the next, with a standard deviation which amounted to $0.51 \%$ of mean body-weight. Edholm (I96I) observed twelve young soldiers in training for 7 weeks, and found daily changes exceeding $0.5 \mathrm{~kg}$ on more than 100 occasions and changes exceeding I $\mathrm{kg}$ on thirty occasions. Durnin (196I) measured the weights of forty-four men living under very controlled conditions and noted changes from day to day as high as $\mathrm{I} \mathrm{kg}$. Taggart (1962) in a study of one woman found losses or gains within $24 \mathrm{~h}$ of up to $0.8 \mathrm{~kg}$.

In our study, nineteen subjects ranging from babies shortly after birth to middleaged adults have been measured to define the extent of daily weight changes in relation to body size, age and sex. With the exception of one pregnant woman in hospital, the subjects were living their ordinary lives.

\section{EXPERIMENTAL}

Subjects. The routine of recording body-weight daily under standard conditions for several weeks is tedious and often awkward to arrange, which inevitably imposes a restriction on the choice of subjects. Three families comprising seven adults and four children co-operated. In addition, five office girls, one of whom was pregnant, were weighed on each working day for 5-6 weeks. The pregnant woman in hospital had been admitted because of a slight haemorrhage, but seemed quite normal during the 5 -week period of observation, during which she continued to reside in hospital as a precaution but was not confined to bed. The two babies were weighed for 2 weeks: the younger during its postnatal period, and the older during healthy convalescence in hospital from a burn, while awaiting arrangements for adoption. Details of the subjects are given in Table $\mathrm{I}$.

Routine of weighing. Standard steelyard personal weighing machines (Avery,

- Present address: Department of Social and Occupational Medicine, The Welsh National School of Medicine, Cardiff. 
Type $3302 \mathrm{ABN}$ ) were used and weights were recorded to $\mathrm{i} \mathrm{oz}$. For the infants, steelyard baby scales were used calibrated in $\frac{1}{4} \mathrm{oz}$.

The weighings were made either without clothing or with a standard amount of clothing and, except for the babies and the five office workers, before breakfast and after emptying the bladder between 7 am and $9 \mathrm{am}$. The office workers were weighed at 9 am on arrival at work. In two families weighings were also made in the evening, with the bladder empty immediately before retiring to bed. It was not possible to control times of defaecation.

Table I. Information about subjects, their mean body-zveights during the period of observation, and deviations of daily fluctuations about the trend of body-weight

\begin{tabular}{|c|c|c|c|c|c|c|c|c|}
\hline Subject & & Occupation & $\begin{array}{c}\text { Age } \\
\text { (years) }\end{array}$ & Sex & $\begin{array}{l}\text { Height } \\
\text { (in.) }\end{array}$ & $\begin{array}{c}\text { Mean } \\
\text { weight (lb) }\end{array}$ & $\begin{array}{l}\mathrm{SD} \\
(\mathrm{lb})\end{array}$ & $\mathrm{Cv}^{*}$ \\
\hline Family I & $\left.\begin{array}{l}1 \\
2 \\
3 \\
4 \\
5\end{array}\right\}$ & $\begin{array}{l}\text { Doctor } \\
\text { Housewife } \\
\text { At school }\end{array}$ & $\begin{array}{r}40 \\
40 \\
\left\{\begin{array}{r}13 \\
11 \\
8\end{array}\right.\end{array}$ & 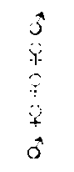 & $\begin{array}{l}71 \cdot 5 \\
64 \cdot 5 \\
63 \cdot 3 \\
62 \cdot 5 \\
54 \cdot 0\end{array}$ & $\begin{array}{r}176 \cdot 5 \\
136 \cdot 2 \\
117 \cdot 7 \\
95 \cdot 7 \\
64 \cdot 4\end{array}$ & $\begin{array}{l}0.82 \\
0.76 \\
0.86 \\
0.49 \\
0.42\end{array}$ & $\begin{array}{l}0.46 \\
0.56 \\
0.73 \\
0.51 \\
0.65\end{array}$ \\
\hline Family 2 & $\begin{array}{l}6 \\
7 \\
8\end{array}$ & $\begin{array}{l}\text { Statistician } \\
\text { Housewife } \\
\text { At school }\end{array}$ & $\begin{array}{l}40 \\
35 \\
12\end{array}$ & $\begin{array}{l}0 \\
0 \\
0 \\
3 \\
3\end{array}$ & $\begin{array}{l}68 \cdot 0 \\
66 \cdot 0 \\
61 \cdot 0\end{array}$ & $\begin{array}{r}177 \cdot 3 \\
154 \cdot 5 \\
98 \cdot 1\end{array}$ & $\begin{array}{l}0.68 \\
0.73 \\
0.52\end{array}$ & $\begin{array}{l}0.39 \\
0.48 \\
0.53\end{array}$ \\
\hline Family 3 & $\begin{array}{l}9 \\
\text { I0 } \\
\text { II }\end{array}$ & $\begin{array}{l}\text { Housewife } \\
\text { Student } \\
\text { Dietician }\end{array}$ & $\begin{array}{l}58 \\
20 \\
36\end{array}$ & $\begin{array}{l}q \\
0 \\
0 \\
0\end{array}$ & $\begin{array}{l}66 \cdot 0 \\
66 \cdot 0 \\
66 \cdot 0\end{array}$ & $\begin{array}{l}184 \cdot 2 \\
152 \cdot 5 \\
140 \cdot 4\end{array}$ & $\begin{array}{l}0.85 \\
1.07 \\
0.88\end{array}$ & $\begin{array}{l}0.46 \\
0.78 \\
0.63\end{array}$ \\
\hline $\begin{array}{l}\text { Pregnant } \\
\text { women }\end{array}$ & $\begin{array}{l}12 \\
13\end{array}$ & $\begin{array}{l}\text { In hospital } \\
\text { Office worker }\end{array}$ & $\begin{array}{l}24 \\
26\end{array}$ & $\frac{6}{9}$ & $\begin{array}{l}63 \cdot 5 \\
66 \cdot 0\end{array}$ & $\begin{array}{l}147.4 \\
163.0\end{array}$ & $\begin{array}{l}0.62 \\
0.73\end{array}$ & $\begin{array}{l}0.42 \\
0.45\end{array}$ \\
\hline $\begin{array}{l}\text { Non-pregnant } \\
\text { women }\end{array}$ & $\left.\begin{array}{l}14 \\
15 \\
16 \\
17\end{array}\right\}$ & Office worker & $\left\{\begin{array}{l}19 \\
26 \\
16 \\
18\end{array}\right.$ & 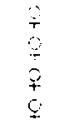 & $\begin{array}{l}65 \cdot 5 \\
63 \cdot 0 \\
61 \cdot 5 \\
63 \cdot 0\end{array}$ & $\begin{array}{l}139 \cdot 3 \\
116.9 \\
109.1 \\
108.6\end{array}$ & $\begin{array}{l}0.66 \\
0.45 \\
0.80 \\
0.64\end{array}$ & $\begin{array}{l}0.47 \\
0.39 \\
0.73 \\
0.59\end{array}$ \\
\hline Babies & $\begin{array}{l}18 \\
19\end{array}$ & - & ${ }_{4}^{I}$ days & $\begin{array}{l}\hat{F} \\
q\end{array}$ & - & $\begin{array}{r}18 \cdot 7 \\
6 \cdot 9\end{array}$ & $\begin{array}{l}0.11 \\
0.04\end{array}$ & $\begin{array}{l}0.59 \\
0.62\end{array}$ \\
\hline
\end{tabular}

When the weight was recorded a note was also made of any unusual deviation from routine in the previous $24 \mathrm{~h}$. Particular note was made of menstruation, ill-health and any departure from normal eating hours and activity.

Statistical methods. In the study of variation it is necessary to take account of the trend of the daily body-weight. Linear and quadratic least square regressions were found adequate to describe the trends. A stationary weight series was defined as one for which the reduction of variation attributable to regression on time was not significant at the $5 \%$ level.

\section{RESLLTS}

Body-weights are shown in graph form in Figs. $1-4$ for those subjects for whom continuous daily weights were available.

Mean body-weight, the standard deviation and the coefficient of variation about the trend are shown for all subjects in 'Table $\mathbf{I}$. 
The coefficients of variation shown in Table 1 ranged from 0.39 to $0.78 \%$. The mean coefficient of variation was $0.54 \%$. The dotted lines in Figs. I-4 make large deviations more obvious. Out of 507 observations, thirty-seven fall at or outside those limits; with nineteen positive and eighteen negative deviations.

Subjects 3 and 16 had two of the highest coefficients of variation (Table I). Reference

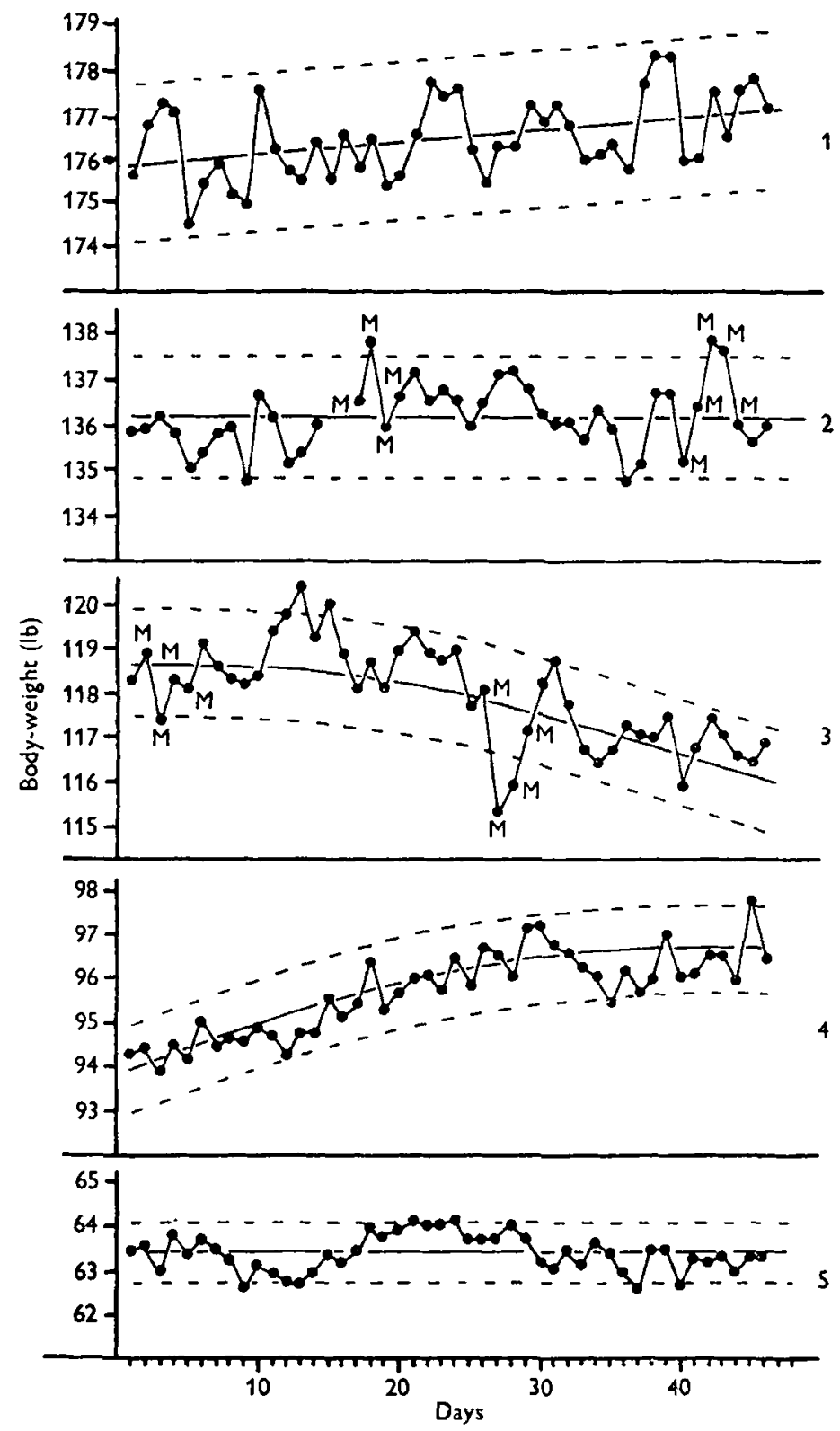

Fig. I. Daily body-weights of family I (subjects $1-5$; see Table $r$ ). The solid line represents the calculated trend during the period of observation; the dotted lines are drawn at a distance of $\pm 1 \%$ of body-weight from trend, i.e. roughly twice the mean SD of the daily fluctuations; $\overline{\mathrm{M}}$, menstruation, 
to Fig. I shows that subject 3 had two episodes of large weight fluctuation. We have no explanation for the first upward fluctuation, but the loss of weight in the second episode can be attributed to a combined effect of cold, menstruation and loss of appetite. If the last two outlying observations are omitted the coefficient of variation becomes $0.59 \%$. The large coefficient of variation in subject 16 was due to one unexplained downward swing of weight of $3 \frac{1}{4} \mathrm{lb}$, the weight returning to the previous

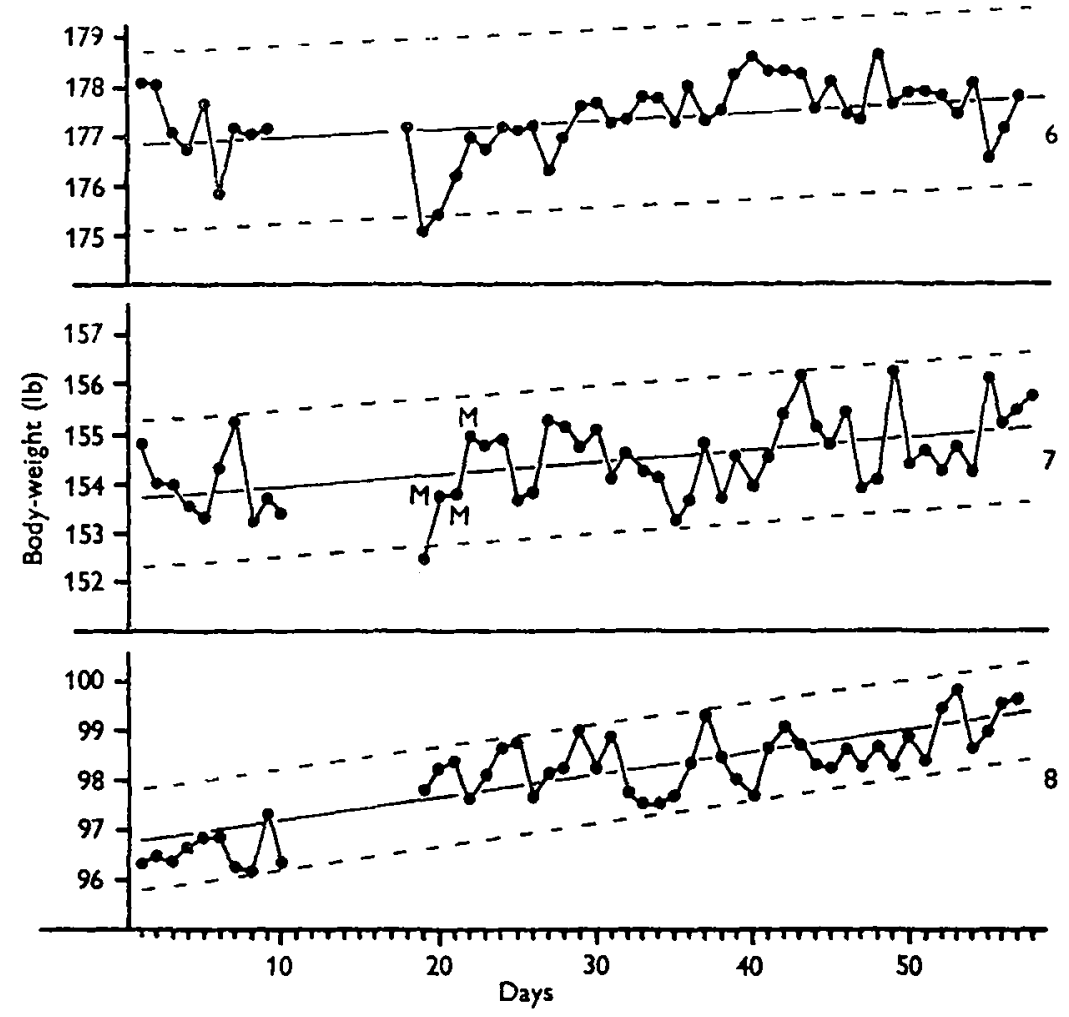

Fig. 2. Daily body-weights of family 2 (subjects 6-8) (see legend to Fig. I).

level the next day. Recovery from such a large weight loss takes usually more than I day, so that it is possible that a recording mistake occurred. If this reading is omitted the coefficient of variation becomes $0.57 \%$.

Subjects 5 , Io and I I also had rather high coefficients of variation. Subject 5 showed no outstanding deviations and we have no explanation for the apparent periodicity of his weight changes. Subjects 10 and $x$ I engaged frequently in strenuous sporting activities. There appears to be no explanation for the outstanding positive deviation of weight in subject 10 ; the loss of weight near the end of the period of observation was associated with an episode of influenza. If the outlying observations are neglected the coefficient of variation is reduced to $0.55 \%$. The outlying observation by the end of the series for subject II was associated with menstruation and a prolonged car journey with limited access to food. In general, the weight fluctuations of subjects 10 and I I did not appear to be related in time to episodes of sporting activity. 


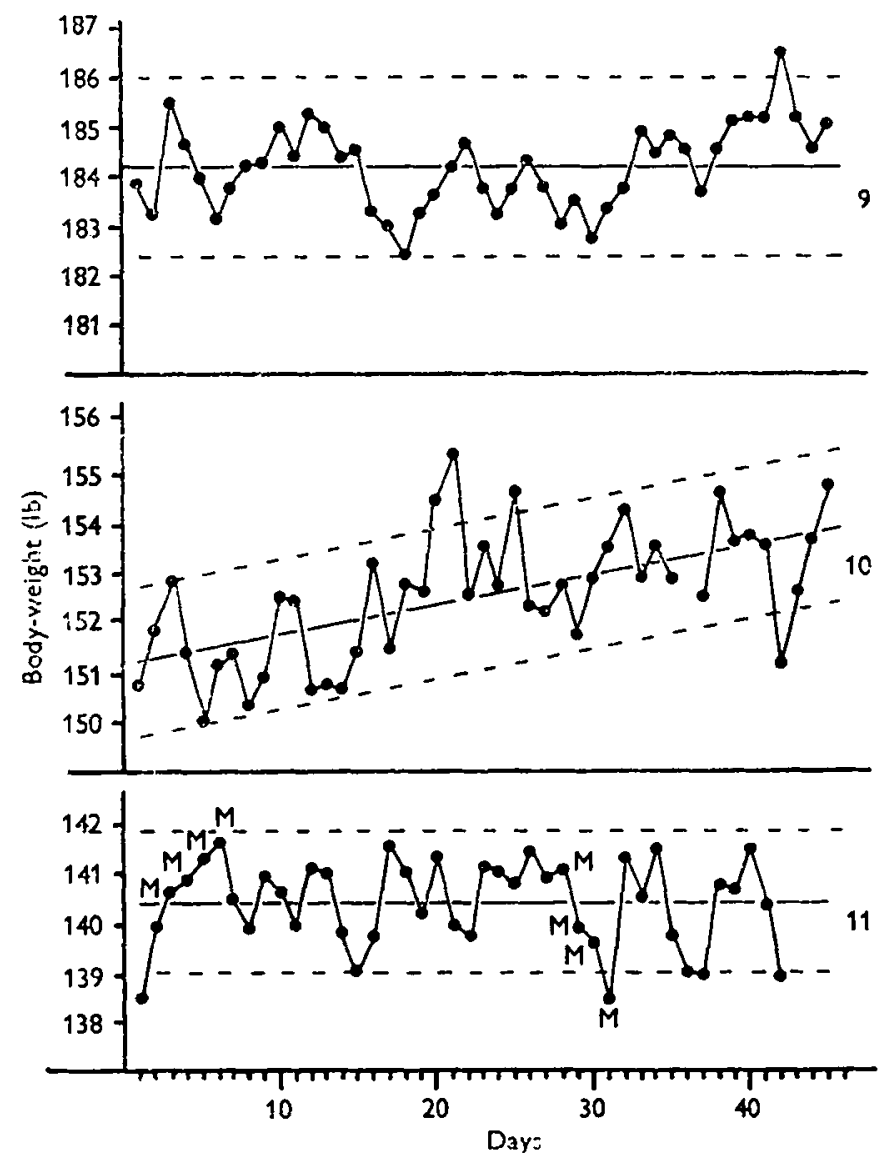

Fig. 3. Daily body-weights of family 3 (subjects 9-1 I) (see legend to Fig. 1).

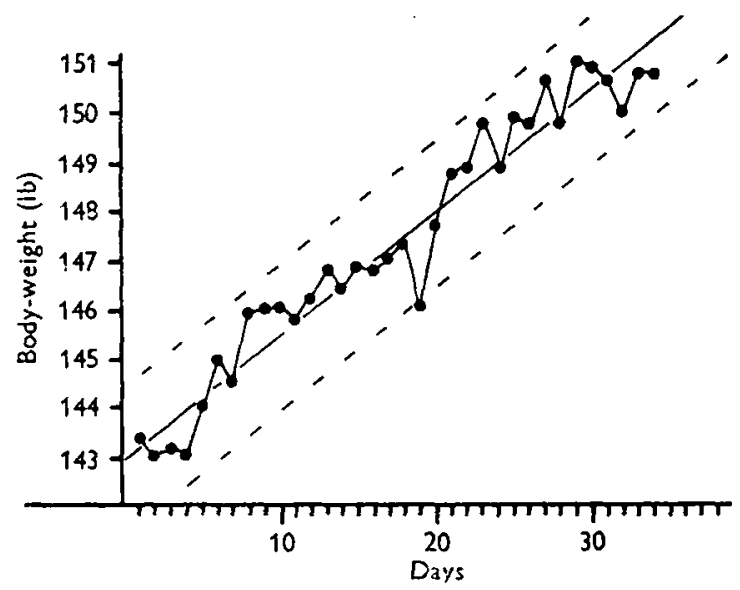

Fig. 4. Daily body-weights of a woman (subject 12) in late pregnancy. (For explanation of lines see legend to Fig. 1.) 
Since menstruation was mentioned twice in the preceding paragraph in association with weight loss it is necessary to state that menstruation appeared to have no consistent effect on weight. Of the seven menstrual periods recorded, one was associated with no change, three with an increase and three with a decrease of weight.

It is not possible to judge from this small series whether there is any relation between the variation of body-weight and either age or sex.

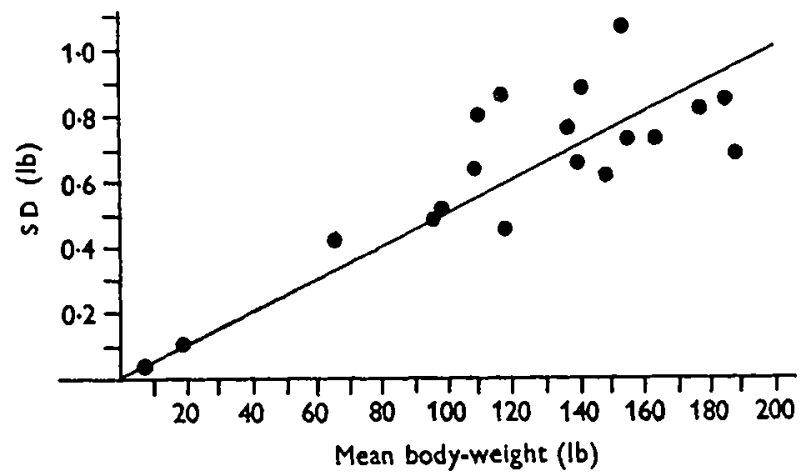

Fig. 5. The SD of daily body-weight fluctuations related to the mean body-weight for each of nineteen subjects. The diagonal line represents a SD equal to $0.5 \%$ of body-weight.

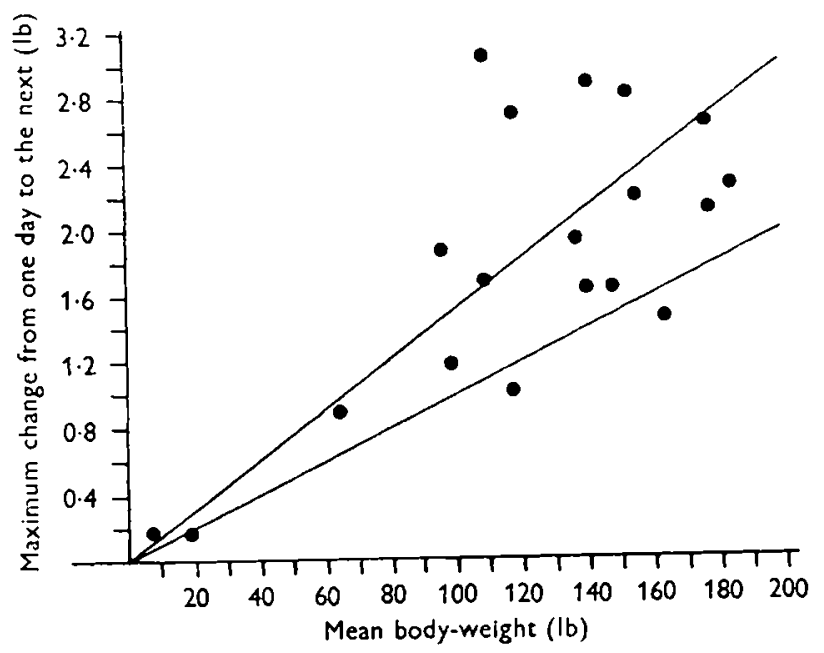

Fig. 6. Maximum daily body-weight changes related to the mean body-weight for cach of nineteen subjects. Two lines, at $\mathrm{I} \%$ (lower) and $\mathrm{I} \cdot 5 \%$ of body-weight are drawn to facilitate assessment of the extent of these deviations.

In Fig. 5 the standard deviations are plotted against body-weight. The diagonal line, representing a SD equal to $0.5 \%$ of body-weight, shows that an approximate linear relation can be assumed to hold for body-weight ranging from 10 to almost $200 \mathrm{lb}$.

The maximum recorded change in body-weight from one day to the next is shown in Fig. 6. This change has a clear relation with mean body-weight. Two lines, at $\mathrm{I}$ and $1.5 \%$ of body-weight, are drawn to facilitate assessment of the extent of these deviations. 
The outlying points in Figs. 5 and 6 represent subjects $3,10,11$ and 16 considered above. The large variation of weight observed in these subjects can, to some extent, be explained by unusual occurrences. It seems reasonable to conclude that under ordinary conditions changes of body-weight from one day to the next tarely exceed $\mathrm{I} \cdot 5 \%$ of body-weight.

Weekends and weekdays. The only consistent differences between weighings on different days was that mean Sunday morning weights were below average. The difference was small and could probably be explained by the subjects' tendency to sleep longer on Sunday mornings.

Serial correlations. When considering body-weight fluctuations about its true or trend value it is of interest to know whether such daily deviations are correlated. For example, if the weight observed on a given day is below the trend, is that observed on the next likely to be below the trend as well? If such a correlation exists it is also useful to know for how many days it persists. Whatever the physiological implications of such correlations, their assessment is of practical importance since they affect the precision with which confidence limits of the true weight change can be calculated and may in addition allow adoption of weighing schemes that, with little extra effort, will be considerably more efficient than taking one measurement at each end of a period of time in establishing whether a change over the period has (or has not) taken place.

Table 2. Morning and evening body-weights of the subjects

\begin{tabular}{cccccc} 
Subject & \multicolumn{4}{c}{ Mean body-weight $(\mathrm{lb})$} & \multicolumn{3}{c}{ Standard deviation (lb) } \\
no. & Morning & Evening & (lb) & Morning & Evening \\
& & & & & \\
I & 176.5 & 178.6 & 2.1 & 0.91 & 0.96 \\
2 & 136.2 & 137.6 & 1.4 & 0.76 & 0.79 \\
3 & 117.7 & 119.1 & 1.4 & 1.16 & 1.28 \\
4 & 95.7 & 97.2 & 1.5 & 0.93 & 1.08 \\
5 & 64.4 & 65.6 & 1.2 & 0.42 & 0.48 \\
6 & 177.3 & 178.4 & 1.1 & 0.73 & 0.86 \\
7 & 154.5 & 157.0 & 2.5 & 0.84 & 1.07 \\
8 & 98.1 & 99.7 & 1.6 & 0.92 & 0.93
\end{tabular}

Although the series are rather short for the purpose, serial correlations between daily deviations from trend were calculated for the first twelve subjects with about forty consecutive observations for each. The correlations between deviations from trend on consecutive days $\left(r_{1}\right)$ were all positive, ranging from 0.18 to 0.60 and can be regarded as homogeneous $\left(\chi_{[11]}^{2}=12 \cdot 1, P \sim 0.35\right)$. (It must be stated here that the usual test for homogeneity is not strictly applicable to serial correlations and should be regarded as an approximate guide only.) The correlations between deviations separated by a gap of I day $\left(r_{2}\right)$ were rather scattered, showing eight positive and four negative values ranging from -0.21 to 0.49 . This set cannot be regarded as homogeneous. Correlations between deviations separated by a 2-day gap $\left(r_{3}\right)$ were again non-homogeneous, ranging from -0.26 to 0.46 with five positive and seven negative

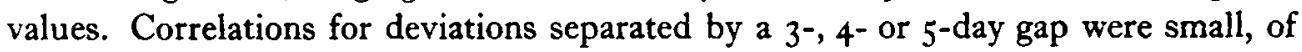
either sign, homogeneous and consistent with the assumption of no correlation. In ten 
out of twelve subjects we have $r_{1}>r_{2}>r_{3}$; serial correlations of high order are small and appear to fluctuate without any pattern.

In view of these results it can be asserted that there is a positive correlation $\rho$ between consecutive deviations from trend and that the correlation between deviations tends to decrease as the time interval between the deviations increases.

Morning and evening body-zveight. Mean body-weights and their variation for eight subjects who were weighed in the morning and the evening are shown in Table 2. The weight was greater in the evening and also more variable.

\section{DISCUSSION}

All the subjects in this study were leading well-ordered lives. The adult subjects were indoor workers and housewives; children were attending schools and the infants were weighed while in hospital. Consequently the findings may not necessarily be applied to other groups. Particularly active persons, labourers or farm workers, for example, might be expected to show larger weight fluctuations, and persons in hospital will almost certainly show a variation of body-weight less than that of our subjects.

The main findings of this study are that the daily variation of body-weight is a function of body-weight itself; that the standard deviation of weight about its trend is close to $0.5 \%$ of the body-weight; that the maximum change from one day to the next rarely exceeds $1.5 \%$ of body-weight, regardless of body size, age or sex; and that daily deviations from the trend of body-weight tend to be positively correlated, the correlation vanishing as the gap between the observations increases.

Table 3. Formulas for the least change in body-weight significant at the $5 \%$ level

- See text, p. 235.

Scheme*
1
2
3
4
5
6

Least change (lb) $\dagger$
$0.0139 \bar{W}$
$0.0116 A \bar{W}$
$0.0106 A \bar{W}$
$0.0101 A \bar{W}$
$0.0103 A \bar{W}$
$0.0093 A \bar{W}$

$m+$
$\circ$
1
2
3
2
3

$+\bar{W}=$ mean of all measurements at both ends of the period. $A=k /(k-m)$ where $k$ is the length of the experiment in days and $m$ is the number of days between the first and last measurement at the beginning or the end of the experiment.

From the physiological point of view the rapid fluctuations of body-weight are very unlikely to be due to growth or loss of solid tissue, and the most likely possibility is that they represent changes of body water content. If so, the extent of variation should be influenced by the mode of life of the subjects, and it would be interesting to compare these results with those of similar studies repeated on different types of subjects in other situations.

When a change in body-weight is observed over a period of time it is necessary to know whether it represents a real difference or may be attributed to daily fluctuations. In addition, to check the compatibility of other experimental results (for example, that a positive nitrogen balance was associated with a gain in weight) the observer may wish 
to know the confidence limits of the true body-weight change. Ideally, change of body-weight should be assessed from the examination of daily weighings. For short experiments this certainly should be the rule. In long-term experiments the finding may be utilized that the deviations from the trend of body-weight for daily measurements, say, 5 days apart are uncorrelated, and weighing every 5 th day arranged. In this way there will be a set of uncorrelated (or almost so) measurements from which good estimates of the rate of body-weight change are easily obtained. However, such a scheme is frequently not practicable and the observer has to be satisfied with a few measurements obtained at the beginning and the end of an experiment. Let us consider this situation in some detail on the basis of the following weighing schemes.

(I) One measurement at each end of the experiment.

(2) Two measurements at each end $24 \mathrm{~h}$ apart.

(3) Two measurements at each end $48 \mathrm{~h}$ apart.

(4) Two measurements at each end $72 \mathrm{~h}$ apart.

(5) Three consecutive daily measurements at each end.

(6) Four consecutive daily measurements at each end.

It will be noticed that when means are taken of the set of $n$ measurements at each end their difference will, for schemes 2-6, refer to a time interval shorter than the whole experiment. For example, in a 10-day experiment there is for scheme 3:

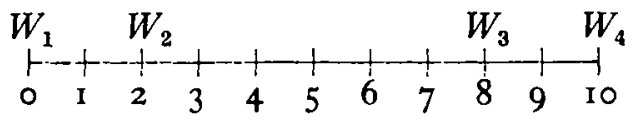

The mean of weights at the beginning of the period refers to time point marked $\mathrm{I}$ on the scale and the mean at the end to time point 9 . The interval between these two points is only 8 days. Since with so few measurements linearity of weight change has to be assumed, the estimate of the change in weight for the full period of 10 days is obtained by multiplying the difference of means of measurements at each end by a constant $A=k^{\prime}(k-m)$, where $k$ is the length of the experiment in days and $m$ is the number of days between the first and the last measurement at the beginning or the end of the experiment. In our example:

$$
\text { Estimated change } c=\left[\frac{W_{3}+W_{4}}{2}-\frac{W_{1}+W_{2}}{2}\right] \times \frac{10}{8} .
$$

To derive the standard deviation of $c$ in order to test its significance or obtain confidence limits of the true change it is necessary to remember that the measurements at each end are correlated. The formulas set out in the Appendix imply a knowledge of the serial correlations in the population. (It will be appreciated that the test for significance of a change in weight can be performed without involving factor $A$, which is in effect a time-scale correction ensuring that the estimated change and the confidence limits correspond to the total length of the experiment.) On the assumption that the correlation between consecutive measurements is $\rho=0.4$ and decreases in powers of $\rho$ as the gap between the measurements increases, $\rho_{1}=0.40, \rho_{2}=0.16, \rho_{3}=0.064$ in terms of the notation used in the section on serial correlations. (The observed mean correlations were $r_{1}=0.37, r_{2}=0.14, r_{3}=0.03$.) Taking the standard deviation of 
daily fluctuations about the trend as $s=0.005 \bar{W}$ gives from (1), (2) and (3) in the Appendix simple formulas for the values of the least change in weight significant at the $5 \%$ level as shown in Table 3 .

It is clear from Table 3 that for a given mean weight the value of the least significant difference depends on the length of the experimental period and the selected scheme of weighing since both determine the value of $A$. Thus with the length of the experimental period taken as fixed the selection of a suitable weighing scheme can be considered. Of the schemes involving two measurements at each end, scheme $\mathbf{2}$ is indicated for experiments lasting up to a fortnight, for longer experiments lasting up to I month scheme 3 is to be preferred, after that scheme 4 is the best. 'The advantage of scheme 3 over scheme 2 or of scheme 4 over scheme 3 increases with the length of the experimental period. Scheme 5 , involving three consecutive measurements, is just about as efficient as the best of the two measurement schemes. For experiments lasting more than a fortnight scheme 6 is appreciably better than any of the other schemes considered here.

The application of formulas in Table 3 to experimental data is very simple. Consider an experiment lasting 20 days for which scheme 3 was selected. Let the two measurements, separated by $48 \mathrm{~h}$, be 149.3 and $148.9 \mathrm{lb}$ at the beginning and 150.5 and ${ }_{15} \mathrm{I}_{3} \mathrm{lb}$ at the end of the experiment. For scheme $3, m=2$ so that $A=20 / 18=$ I.II , the mean of all measurements is $150.0 \mathrm{lb}$, so that from Table 3 the least difference significant at the $5 \%$ level is $\mathrm{I} \cdot 76 \mathrm{lb}$. The estimate of the difference for the experimental period is the difference of the means at the two ends multiplied by $A$ or $(150.9-149.1) I \cdot I I I=2.0 \mathrm{lb}$. Thus the change of weight is unlikely to be due to chance and the $95 \%$ confidence limits for the true change are $2 \cdot 0 \pm \mathrm{r} \cdot 76 \mathrm{lb}$. Had scheme I been used the least significant difference would be $2.09 \mathrm{lb}$ (since the mean of the first and last measurement is $150^{\circ} 3 \mathrm{lb}$ ) so that the observed difference of $15 \mathrm{I} \cdot 3-$ $149.3=2 \cdot 0 \mathrm{lb}$ would not be significant and the $95 \%$ confidence limits $2 \cdot 0 \pm 2.09$ would be appreciably wider.

Table 4. Comparison of the least difference (lb) significant at the $5 \%$ level

(For mean body-weight of $150 \mathrm{lb}$ )

\begin{tabular}{ccccc} 
& \multicolumn{4}{c}{ Length of the experiment (days) } \\
Scheme & -15 & 20 & 25 & 30 \\
I & 2.08 & 2.08 & 2.08 & 2.08 \\
3 & 1.82 & 1.76 & 1.72 & 1.70 \\
6 & 1.74 & 1.64 & 1.58 & 1.55 \\
& & &
\end{tabular}

To see what gain in accuracy is likely to result from the use of these schemes let us compare the values for the least difference significant at the $5 \%$ level. A comparison of schemes I, 3 and 6 for experiments of varying length is shown in Table 4 .

Table 4 shows that the differences are appreciable. For example, with a 20-day experimental period the $95 \%$ confidence limits may be narrowed by $0.9 \mathrm{lb}$ by using 
scheme 6 or by $0.6 \mathrm{lb}$ by using scheme 3 instead of scheme $\mathrm{I}$ (since the $95 \%$ confidence limits are twice the least significant difference at the $5 \%$ level).

The above calculations are based on an assumed pattern of serial correlations. Since, as pointed out earlier, the correlations were widely scattered it is necessary to say a word about the sensitivity of the procedure with respect to the assumptions made about the values and pattern of serial correlations.

Let us take three sets of correlations:

(1) $r_{1}=0.40, r_{2}=0.16, r_{3}=0.064$ (as assumed),

(2) $r_{1}=0.40, r_{2}=0.30, r_{3}=0.20$,

(3) $r_{1}=0.60, r_{2}=0.50, r_{3}=0.40$,

and tabulate the least significant difference for schemes $\mathrm{I}, 3$ and 6 . The results are presented in Table 5 , which shows that the values for the very extreme set 3 differ considerably from those for set $I$, while the values for set 2 are intermediate. The second part of Table 5 shows the approximate significance levels which would obtain if the formulas of Table 3 were applied to a population wi:h serial correlations specified by sets 2 and 3 . The effect is obviously not very great, considering that correlations in set 3 are, judging from our data, unusually high

It is concluded therefore that the formulas in Table 3 give an objective, if approximate, method of assessing the significance of an observed weight difference and of the limits within which the true difference is likely to be.

\section{Table 5. Effect of different sets of serial correlations}

(Length of experiment $=30$ days, average weight $=150 \mathrm{lb}$ )

\begin{tabular}{|c|c|c|c|c|c|}
\hline \multirow[b]{2}{*}{ Scheme* } & \multicolumn{3}{|c|}{ Least difference (lb) significant at $5 \%$} & \multicolumn{2}{|c|}{ Approx. true s.gnificant le } \\
\hline & Set It & Set $2 \nmid$ & Set $3 t$ & Set 2 & Set 3 \\
\hline $\mathbf{I}$ & 2.08 & $2 \cdot 08$ & 2.08 & $5.0 \%$ & $5.0 \%$ \\
\hline 3 & $I \cdot 70$ & $1 \cdot 79$ & I.93 & $6.4 \%$ & $8.6 \%$ \\
\hline 6 & $I \cdot 55$ & $I \cdot 63$ & $\mathrm{I} \cdot 88$ & $6 \cdot 3 \%$ & $10.3 \%$ \\
\hline
\end{tabular}

- See text, p. 235 .

+ See text, p. 237.

1 When formulas given in Table 3 , based on set 1 , are used to test differences for populations with serial correlations given by set 2 or 3 .

\section{S UMMARY}

I. Day-to-day weight changes of nineteen subjects have been studied for a period of $30-40$ days.

2. The extent of daily fluctuations of body-weight was found to be related to bodyweight itself.

3. The standard deviation of body-weight fluctuations about its trend was close to $0.5 \%$ of the body-weight.

4. The maximum change of body-weight from one day to the next rarely exceeded $1.5 \%$ of body-weight regardless of body size, age or sex.

5. Daily deviations from the trend of body-weight tended to bie positively correlated, the correlation disappearing as the gap between the observations increased. 
6. Formulas for approximate assessment of significance of body-weight changes are presented.

7. The need to compare these results with studies on different types of subjects is emphasized.

We are greatly indebted to all those who participated in this study for their cooperation, to our colleagues in the Obstetric Medicine Research Unit for their help and encouragement and to Mr A. W. Boyne for helpful suggestions which have been incorporated in the paper.

\section{APPENDIX}

\section{Derivation of results in Table 3}

Let $Y_{i}, Y_{j}$ be the body-weight readings in $i$ th and $j$ th days respectively. $Y_{i}$ and $Y_{j}$ are likely to be more alike when $i$ and $j$ are close together than when they are distant. I et $\rho_{i j}$ be the correlation between the adjusted values of $Y_{i}$ and $Y_{j}$ (adjusted for the trend) and the variance of $Y_{i}$ and $Y_{j}$ about the trend be $\sigma^{2}$. The correlation $\rho_{i j}$ is a function of $(i-j)$ and tends to zero as the gap $|i-j|$ is increased.

Further $\operatorname{cov}\left(Y_{i}, Y_{j}\right)=\sigma^{2}{ }_{i j}=\rho_{i j} \sigma^{2}$, where $j=i+1, i+2 \ldots$

Let us consider a weighing experiment in which $n$ body-weight measurements are recorded on $n$ separate days at each end of a time interval long enough to allow us to disregard the correlation between the initial and the final set of readings.

We have

$$
\begin{aligned}
& \bar{Y}_{b}=\frac{\sum_{i=1}^{n} Y_{b_{i}}}{n} \text { mean body-weight at the beginning of experiment, } \\
& \bar{Y}_{e}=\frac{\sum_{i=1}^{n} Y_{e_{i}}}{n}-\text { mean body-weight at the end of experiment }
\end{aligned}
$$

and since we wish the estimated change of body-weight to refer to the beginning and the end of the observation period, and with few readings at both ends of the period, we have to assume linearity of growth so that the estimated change in body-weight, $c=[k /(k-m)]\left(\bar{Y}_{e}-\bar{Y}_{b}\right)$, and the variance of change $c$,

$$
V=\left(\begin{array}{c}
k \\
k-m
\end{array}\right)^{2}\left(V\left(\bar{Y}_{e}\right)+V\left(\bar{Y}_{b}\right)\right)
$$

$k$ is the number of days between the first and last measurements of the observation period and $m$ is the number of days between the first and the last measurements of the $n$ measurements at the beginning of the period.

For a symmetrical set of $n$ measurements at each end of the time interval we have

Thus

$$
V\left(\bar{Y}_{e}\right)=V\left(\bar{Y}_{b}\right) \text {. }
$$

$$
V(c)=2\left(\frac{k}{k-m}\right)^{2} V\left(\bar{Y}_{b}\right)
$$


Now,

$$
\begin{aligned}
V\left(\bar{Y}_{b}\right) & =V\left(\frac{Y_{b_{1}}+Y_{b_{2}}+\ldots+Y_{b_{n}}}{n}\right) \\
& =\frac{1}{n^{2}}\left(n o^{2}+2 \sum_{i=1}^{n-1} \sum_{j=i+1}^{n} \sigma_{i j}\right) \\
& =\frac{\sigma^{2}}{n^{2}}\left(n+2 \sum_{i=1}^{n-1} \sum_{j=i+1}^{n} \rho_{i j}\right) .
\end{aligned}
$$

Equation (2) shows that positive correlations $\rho_{i j}$ within the set of $n$ readings inflate the variance of the mean $V\left(\bar{Y}_{b}\right)$.

In the special case when all $\rho_{i j}=0, V\left(\bar{Y}_{b}\right)=\sigma^{2} / n$. Barring negative correlations, this is the minimum obtainable variance. This minimum is likely to be achieved when $(i-j)>4$.

Under the hypothesis of a true change

$$
\begin{aligned}
& C=\left(\frac{k}{k-m}\right)\left(\mu_{e}-\mu_{b}\right), \\
& Z=\frac{c-C}{[V(c)]^{\frac{1}{2}}} \text { is a normal variate with zero mean and unit variance. }
\end{aligned}
$$

In the above expression $\sigma^{2}$ and $\rho_{t j}$ are unknown quantities needed to estimate $V(c)$ from ( 1 ) and (2). If we substitute $s^{2}$ and $r_{i j}$ (the estimate as discussed in the paper), normal distribution is still valid, and the $95 \%$ confidence limits for the true change $C$ are given by

$$
c-1 \cdot 96 \sqrt{ }[\hat{V}(c)]<C<c+1 \cdot 96 \sqrt{ }[\hat{V}(c)] .
$$

The weakness of the estimates of $\rho_{i j}$ was pointed out in the paper. The estimate of $s^{2}$ is obtained from the relation $s=0.005 \bar{Y}$, where $\bar{Y}$ is the mean of all measurements.

\section{REFERENCES}

Durnin, J. V. G. A. (196r). Proc. Nutr. Soc. 20, 52.

Edholm, O. G. (1961). Proc. Nutr. Soc. 20, 71.

Elkinton, J. R. \& Danowski, T. S. (1955). The Body Fluids. Chapter 1, p. 26. Baltimore, Md: The Williams and Wilkins Co.

Taggart, N. (1 962). Brit. F. Nutr. 16, 223. 